\title{
Hubungan Pola Makan dan Tingkat Stres terhadap Kekambuhan Gastritis di Wilayah Kerja Puskesmas Tarok Kota Payakumbuh Tahun 2017
}

\author{
Widiya Tussakinah ${ }^{1}$, Masrul ${ }^{2}$, Ida Rahmah Burhan ${ }^{3}$
}

\begin{abstract}
Abstrak
Gastritis adalah proses inflamasi yang disebabkan oleh faktor iritasi dan infeksi pada mukosa dan s ubmukosa lambung. Gastritis dapat mengalami kekambuhan yang dipengaruhi oleh pola makan dan stres. Tujuan penelitian ini adalah menentukan hubungan pola makan dan tingkat stres terhadap kekambuhan gastritis pada masyarakat wilayah kerja puskesmas Tarok kota Payakumbuh tahun 2017. Jenis penelitian adalah deskriptif analitik dengan desain crosssectional study. Populasi dalam penelitian ini adalah semua pasien gastritis Puskesmas Tarok kota Payakumbuh tahun 2017. Terdapat sembilan puluh sampel yang diambil dengan teknik systematic random sampling. Instrumen penelitian ini adalah kuesioner untuk mendapatkan data pola makan, tingkat stres dan kekambuhan gastritis responden. Data dianalisis dengan Chi-square untuk pola makan dan kekambuhan gastritis dan Kruskall-wallis untuk tingkat stres dan kekambuhan gastritis. Hasil univariat didapatkan prevalensi kambuh $(55,6 \%)$, sampel dengan pola makan kurang baik $(20 \%)$ dan sampel dengan tingkat stres berat $(26,7 \%)$. Hasil analisis bivariat menunjukkan ada hubungan antara pola makan dengan kekambuhan gastritis $(p=0,000)$ dan juga ada hubungan antara tingkat stres dengan kekambuhan gastritis $(p=0,000)$. Simpulan penelitian ini adalah terdapat hubungan bermakna antara pola makan dan tingkat stres dengan kekambuhan gastritis pada masyarakat wilayah kerja Puskesmas Tarok kota Payakumbuh tahun 2017.
\end{abstract}

Kata kunci: pola makan, tingkat stres, kekambuhan gastritis di Puskesmas Tarok

\section{Abstract}

Gastritis is an inflammatory process caused by irritation and infection factors in the mucous and submucous of the stomach. Gastritis could has a relapse that is affected by diet and stress. The objective of this study was to determine the correlation between eating patterns and stress levels on the relapse of gastritis in the community at Puskesmas Tarok of Payakumbuh's city in 2017. The type of research was descriptive analytic with cross-sectional study design. The population of this research were all patient with gastritis in Puskesmas Tarok in 2017. There were ninety samples takes with systematic random sampling technique. The instrument of this study was a questionnaire to get dietary data, stress levels and relapse of gastritis respondents. The data were analyzed by Chi-square for diet and relapse of gastritis and Kruskall-wallis for stress levels and relapse of gastritis. The univariate result showed (55,6\%) relapse prevalence, sample with poor diet (20\%) and sample with weight level (26,7\%). The result of bivariate analysis showed there were a correlation between eating patterns with gastritis relapse $(p=0,000)$ and also there was a correlation between stress levels and relapse of gastritis $(p=0,000)$. The conclusion of this research is the significant correlation between eating patterns and stress levels on the relapse of gastritis in the community at Puskesmas Tarok of Payakumbuh's city in 2017.

Keywords: eating patterns, stress levels, relapse of gastritis at Puskesmas Tarok 
Affiliasi penulis: 1. Prodi Kedokteran Fakultas Kedokteran Universitas Andalas Padang (FK Unand), 2. Bagian Gizi FK Unand, 3. Bagian Kesehatan Masyarakat FK Unand

Korespondensi: Widiya Tussakinah, Email:

widiyatussakinah@gmail.com,Telp: 085264207827

\section{PENDAHULUAN}

Penyakit Tidak Menular (PTM) menjadi penyebab utama kematian secara global. Proporsi penyebab kematian PTM pada orang-orang berusia < 70 tahun; penyakit cardiovascular (39\%), diikuti kanker (27\%), sedangkan penyakit pernafasan kronis, penyakit pencernaan dan PTM lain menyebabkan sekitar $30 \%$, serta $4 \%$ kematian akibat diabetes. Gastritis merupakan salah satu masalah saluran pencernaan yang paling sering terjadi dan paling sering dijumpai di klinik karena diagnosisnya sering hanya berdasarkan gejala klinis bukan pemeriksaan histopatologi. Gastritis dianggap sebagai suatu hal yang remeh namun gastritis merupakan awal dari suatu penyakit yang dapat mengganggu kualitas hidup seseorang. ${ }^{(1),(2)}$

Badan penelitian kesehatan WHO mengadakan tinjauan terhadap beberapa negara dunia dan mendapatkan hasil dari angka persentase kejadian gastritis di dunia , diantaranya Inggris $22 \%$, China $31 \%$, Jepang $14,5 \%$, Kanada $35 \%$, dan Prancis 29,5\%. Insiden gastritis di Asia Tenggara sekitar 583.635 dari jumlah penduduk setiap tahunnya. Angka kejadian gastritis yang dikonfirmasi melalui endoskopi pada populasi di Shanghai sekitar 17,2\% yang secara substansial lebih tinggi daripada populasi di barat yang berkisar $4,1 \%$ dan bersifat asimptomatik. Persentase dari angka kejadian gastritis di Indonesia menurut WHO adalah $40,8 \%$ dan angka kejadian gastritis di beberapa daerah di Indonesia cukup tinggi dengan angka kejadian 274.396 kasus dari 238.452.952 jiwa penduduk. Berdasarkan profil kesehatan Indonesia tahun 2011, gastritis merupakan salah satu penyakit dari 10 penyakit terbanyak pada pasien rawat inap di rumah sakit di Indonesia dengan jumlah 30.154 kasus (4,9 \%). Berdasarkan data Dinas Kesehatan Provinsi Sumatera Barat, gastritis menempati urutan ke-3 dari 10 penyakit terbanyak di Sumatera Barat tahun 2014 yaitu sebesar 86.874 kasus $(10,94 \%) .{ }^{(3),(4),(5),(6)}$
Gastritis adalah proses inflamasi atau gangguan kesehatan yang disebabkan oleh faktor iritasi dan infeksi pada mukosa dan submukosa lambung. Gastritis dapat menyerang seluruh lapisan masyarakat dari semua tingkat usia maupun jenis kelamin tetapi dari beberapa survei menunjukkan bahwa gastritis paling sering menyerang usia produktif. Pada usia produktif masyarakat rentan terserang gejala gastritis karena dari tingkat kesibukan, gaya hidup yang kurang memperhatikan kesehatan serta stres yang mudah terjadi. Gastritis dapat mengalami kekambuhan dimana kekambuhan yang terjadi pada penderita gastritis dapat dipengaruhi oleh pengaturan pola makan yang tidak baik dan juga dipengaruhi oleh faktor stres. ${ }^{(7),(8),(9)}$

Pola makan adalah susunan jenis dan jumlah makanan yang dikonsumsi seseorang atau kelompok orang pada waktu tertentu terdiri dari frekuensi makan, jenis makanan, dan porsi makan. Menu seimbang perlu dimulai dan dikenal dengan baik sehingga akan terbentuk kebiasaan makan makanan seimbang dikemudian hari. Kebiasaan makan adalah istilah yang digunakan untuk menggambarkan kebiasaan dan perilaku yang berhubungan dengan pengaturan pola makan. Pola makan yang tidak teratur dan tidak baik dapat menyebabkan gangguan di sistem pencernaan. Dalam penelitian Sulastri (2012) jumlah dan frekuensi makan perlu di perhatikan untuk meringankan pekerjaan saluran pencernaan dimana sebaiknya makan tiga kali sehari dalam porsi kecil. Jenis makanan merangsang perlu diperhatikan agar tidak merusak lapisan mukosa lambung. ${ }^{(9),(10),(11)}$

Gastritis biasanya diawali dengan pola makan yang tidak baik dan tidak teratur sehingga lambung menjadi sensitif di saat asam lambung meningkat. Peningkatan asam lambung diluar batas normal akan menyebabkan terjadinya iritasi dan kerusakan pada lapisan mukosa dan submukosa lambung dan jika peningkatan asam lambung ini dibiarkan saja maka kerusakan lapisan lambung atau penyakit gastritis akan semakin parah. Dalam penelitian Gustin (2012) menunjukkan bahwa dari 30 responden yang mengalami gastritis didapatkan proporsi kejadian gastritis lebih tinggi pada responden yang mempunyai 
kebiasaan makan yang kurang baik (100\%) dibanding responden dengan kebiasaan makan yang baik (22\%). Dalam penelitian Maulidiyah (2006) dari 90 orang responden didapatkan bahwa jumlah responden yang mengalami kekambuhan sebanyak 54 responden $(77,1 \%)$ mempunyai kebiasaan makan yang kurang baik dan sebanyak 16 responden $(22,9 \%)$ mempunyai kebiasaan makan yang baik. Pengaturan pola makan yang tidak baik dan tidak teratur akan menimbulkan kekambuhan pada penderita gastritis. Oleh karena itu pengaturan pola makan yang baik dan teratur merupakan salah satu dari penatalaksanaan gastritis dan juga merupakan tindakan preventif dalam mencegah kekambuhan gastritis. ${ }^{(4),(8),(12),(13)}$

Stres adalah sekumpulan perubahan fisiologis akibat tubuh terpapar terhadap bahaya atau ancaman. Stres dapat menimbulkan suatu pengaruh yang tidak menyenangkan pada seseorang berupa gangguan atau hambatan dalam pengobatan, meningkatkan resiko kesakitan seseorang, menimbulkan kembali penyakit yang sudah mereda, mencetuskan atau mengeksaserbasi suatu gejala dari kondisi medis umum. Stres memiliki efek negatif melalui mekanisme neuroendokrin terhadap saluran pencernaan sehingga beresiko untuk mengalami gastritis. Produksi asam lambung akan meningkat pada keadaan stres, misalnya pada beban kerja berat, panik tergesa-gesa. Kadar asam lambung yang meningkat dapat mengiritasi mukosa lambung dan jika hal ini dibiarkan maka dapat menyebabkan terjadinya peradangan mukosa lambung atau gastritis. ${ }^{(13),(14),(15),(16)}$

Berdasarkan hasil wawancara dalam suatu penelitian yang dilakukan oleh Gustin (2012) menunjukkan bahwa dari 30 responden yang mengalami gastritis didapatkan bahwa proporsi kejadian gastritis lebih tinggi pada responden yang mengalami stres $(70,8 \%)$ dibanding yang tidak mengalami stres $(17,1 \%)$. Seseorang yang sudah menderita gastritis apabila dalam keadaan stres dapat menyebabkan terjadinya kekambuhan gastritis. Sedangkan dalam penelitian Maulidiyah (2006) dari 90 orang responden didapatkan bahwa jumlah responden yang mengalami kekambuhan dalam kondisi stres lebih banyak pada penderita gastritis yang mengalami stres yaitu sebanyak 59 responden $(84,3 \%)$ dari pada yang tidak mengalami stres yaitu sebanyak 11 responden (15,7\%). Stres memiliki pengaruh terhadap kejadian gastritis dan juga berpengaruh terhadap kekambuhan pada penderita gastritis. Oleh karena itu pengendalian secara efektif berupa istirahat cukup, olahraga teratur dan relaksasi yang cukup serta dukungan positif dapat mengurangi tingkat stres pada seseorang sehingga akan membantu dalam upaya perawatan dan pencegahan kekambuhan gastritis. $^{(4),(7),(13),(15),(17)}$

Berdasarkan data yang diperoleh dari Dinas Kesehatan Kota Payakumbuh tahun 2014, menyebutkan bahwa gastritis menempati urutan ke-4 dari 10 penyakit terbanyak dengan jumlah 3.995 kasus , pada tahun 2015 meningkat menjadi 4.962 kasus dan pada tahun 2016 meningkat menjadi 5774 kasus . Dan pada bulan Januari - Agustus tahun 2017 diperoleh data tentang kejadian gastritis dari 8 puskesmas yang ada di Kota Payakumbuh, dimana puskesmas yang tertinggi angka kejadian gastritisnya adalah puskesmas Tarok dengan jumlah 987 orang penderita gastritis. ${ }^{(18),}$

Adanya peningkatan angka kejadian gastritis di kota Payakumbuh, terutama angka kejadian gastritis tertinggi di Puskesmas Tarok, sehingga perlu dilakaukan penelitian tentang hubungan pola makan dan tingkat stres terhadap kekambuhan gastritis di wilayah kerja puskesmas Tarok kota Payakumbuh pada tahun 2017 . Sehingga kedepannya diharapkan penyebab kasus pada penderita gastritis ini dapat diperbaiki agar dapat mengurangi dari angka kejadian dan kekambuhan gastritis ini.

\section{METODE}

Jenis penelitian yang ini adalah deskriptif analitik dengan pendekatan cross-sectional study. Penelitian ini dilakukan setelah mendapat kelayakan etik (ethical clearance) dari Komisi Etik Penelitian Fakultas Kedokteran Universitas Andalas dengan nomor surat 536/KEP/FK/2017.

Populasi penelitian ini adalah semua pasien dengan kejadian gastritis di Puskesmas Tarok Kota Payakumbuh tahun 2017 dengan jumlah sampel sebanyak 90 responden yang diambil dengan menggunakan teknik systematic random sampling. 
Kriteria inklusi penelitian ini adalah penderita yang terdiagnosis mengalami kejadian gastritis dan bersedia untuk diwawancarai, sedangkan kriteria eksklusi adalah penderita yang tiba-tiba sakit atau penderita yang tidak bisa ditemui setelah dua kali kunjungan.

Data penelitian terdiri dari data primer dan data sekunder. Data primer didapatkan dari wawancara menggunakan kuesioner, sedangkan data sekunder berupa pencatatan dan pelaporan kejadian gastritis dari bulan Januari sampai Oktober 2017. Data yang sudah terkumpul diolah dan dianalisis dengan menggunakan software pada komputer.

Analisis dilakukansecara bertahap yaitu analisis univariat dan bivariat. Analisis univariat untuk melihat distribusi frekuensi variabel yang diteliti. Analisis bivariat untuk melihat hubungan antara variabel independen dengan variabel dependen menggunakan uji Chi-square dengan derajat kepercayaan 95\% $(\alpha=0,05)$. Jika menggunakan tabel $>2 \times 2$ dan ditemui nilai harapan kurang dari 5 , maka digunakan uji Kruskall-wallis. ${ }^{(19)}$

\section{HASIL}

Penelitian ini dilakukan terhadap 90 subjek penelitian di wilayah kerja Puskesmas Tarok kota Payakumbuh.

Tabel 1. Distribusi frekuensi responden berdasarkan kelompok usia

\begin{tabular}{lcc}
\hline \multicolumn{1}{c}{ Umur } & $\begin{array}{c}\text { Frekuensi } \\
(\mathbf{f})\end{array}$ & $\begin{array}{c}\text { Persentase } \\
(\%)\end{array}$ \\
\hline $12-16$ tahun & 5 & 5,5 \\
$17-25$ tahun & 7 & 7,8 \\
$26-35$ tahun & 14 & 15,5 \\
$36-45$ tahun & 16 & 17,8 \\
$46-55$ tahun & 25 & 27,8 \\
$56-65$ tahun & 15 & 16,7 \\
$>65$ tahun & 8 & 8,9 \\
\hline Total & 90 & 100 \\
\hline Rerata & $44,74 \pm 15,307$ & \\
\hline
\end{tabular}

Tabel 1 menunjukkan bahwa penderita gastritis yang diteliti terbanyak pada responden dengan kelompok umur 46-55 tahun ( $27,8 \%$ ) dimana rerata umur responden adalah 44,74 $\pm 15,307$.

Tabel 2. Distribusi frekuensi responden berdasarkan jenis kelamin

\begin{tabular}{lcc}
\hline Jenis kelamin & $\begin{array}{c}\text { Frekuensi } \\
(\mathbf{f})\end{array}$ & $\begin{array}{c}\text { Persentase } \\
(\mathbf{\%})\end{array}$ \\
\hline Laki-laki & 25 & 27,8 \\
Perempuan & 65 & 72,2 \\
\hline Total & 90 & 100 \\
\hline
\end{tabular}

Tabel 2 menunjukkan bahwa penderita gastritis yang diteliti terbanyak pada responden dengan jenis kelamin perempuan $(72,2 \%)$.

Tabel 3. Distribusi frekuensi responden berdasarkan pendidikan

\begin{tabular}{lcc}
\hline Pendidikan & $\begin{array}{c}\text { Frekuensi } \\
(\mathbf{f})\end{array}$ & $\begin{array}{c}\text { Persentase } \\
(\boldsymbol{\%})\end{array}$ \\
\hline SD & 28 & 31,1 \\
SMP & 15 & 16,7 \\
SMA & 28 & 31,1 \\
Perguruan Tinggi & 19 & 21,1 \\
\hline Total & 90 & 100 \\
\hline
\end{tabular}

Tabel 3 menunjukkan bahwa penderita gastritis yang diteliti terbanyak pada responden dengan pendidikan SD dan SMA $(62,2 \%)$.

Tabel 4. Distribusi frekuensi responden berdasarkan pekerjaan

\begin{tabular}{lcc}
\hline Pekerjaan & $\begin{array}{c}\text { Frekuensi } \\
(\mathbf{f})\end{array}$ & $\begin{array}{c}\text { Persentase } \\
(\mathbf{\%})\end{array}$ \\
\hline PNS & 5 & 5,6 \\
Karyawan & 8 & 8,9 \\
lbu rumah tangga & 31 & 34,4 \\
Pelajar & 10 & 11,1 \\
Wiraswasta & 11 & 12,2 \\
Buruh & 17 & 18,9 \\
Pensiunan & 8 & 8,9 \\
\hline Total & 90 & 100 \\
\hline
\end{tabular}


Tabel 4 menunjukkan bahwa penderita gastritis yang diteliti terbanyak pada responden lbu rumah tangga ( $34,4 \%)$.

Tabel 5. Distribusi frekuensi responden berdasarkan kekambuhan gastritis

\begin{tabular}{|c|c|c|}
\hline Variabel Dependen & $\begin{array}{c}\text { Frekuensi } \\
\text { (f) }\end{array}$ & $\begin{array}{c}\text { Persentase } \\
(\%)\end{array}$ \\
\hline \multicolumn{3}{|l|}{ Kekambuhan Gastritis } \\
\hline - Kambuh & 50 & 55,6 \\
\hline Tidak kambuh & 40 & 44,4 \\
\hline Total & 90 & 100 \\
\hline
\end{tabular}

Tabel 5 menunjukkan bahwa mayoritas responden mengalami kekambuhan 55,6\% .

Tabel 6. Distribusi frekuensi responden berdasarkan pola makan

\begin{tabular}{lcc}
$\begin{array}{l}\text { Variabel } \\
\text { Independen }\end{array}$ & $\begin{array}{c}\text { Frekuensi } \\
(\mathbf{f})\end{array}$ & $\begin{array}{c}\text { Persentase } \\
(\%)\end{array}$ \\
\hline Pola makan & 72 & 80 \\
-baik & 18 & 20 \\
-kurang baik & 90 & 100 \\
\hline Total & & \\
\hline
\end{tabular}

Tabel 6 menunjukkan bahwa mayoritas responden memiliki pola makan yang baik $80 \%$.

Tabel 7. Distribusi frekuensi responden berdasarkan tingkat stress

\begin{tabular}{lcc}
$\begin{array}{l}\text { Variabel } \\
\text { Independen }\end{array}$ & $\begin{array}{c}\text { Frekuensi } \\
(\mathbf{f})\end{array}$ & $\begin{array}{c}\text { Persentase } \\
(\%)\end{array}$ \\
\hline Tingkat stress & & \\
- normal & 8 & 8,9 \\
- ringan & 23 & 25,6 \\
- Sedang & 23 & 25,6 \\
- berat & 24 & 26,7 \\
- cukup berat & 12 & 13,3 \\
\hline \multirow{2}{*}{ Total } & & 100 \\
\hline
\end{tabular}

Tabel 7 menunjukkan bahwa mayoritas responden memiliki tingkat stres berat $26,7 \%$.
Tabel 8. Hubungan pola makan dengan kekambuhan gastritis

\begin{tabular}{|c|c|c|c|c|c|c|c|}
\hline \multirow{3}{*}{$\begin{array}{c}\text { Pola } \\
\text { makan }\end{array}$} & \multicolumn{4}{|c|}{$\begin{array}{c}\text { Kekambuhan } \\
\text { gastritis }\end{array}$} & \multirow{2}{*}{\multicolumn{2}{|c|}{ Total }} & \multirow{3}{*}{ p } \\
\hline & \multicolumn{2}{|c|}{ Kambuh } & \multicolumn{2}{|c|}{$\begin{array}{c}\text { Tidak } \\
\text { kambuh }\end{array}$} & & & \\
\hline & $f$ & $\%$ & $f$ & $\%$ & $f$ & $\%$ & \\
\hline Baik & 32 & 44,4 & 40 & 55,6 & 72 & 100 & \\
\hline $\begin{array}{l}\text { Kurang } \\
\text { baik }\end{array}$ & 18 & 100 & 0 & 0 & 18 & 100 & 0,00 \\
\hline Total & 50 & 55,6 & 40 & 44,6 & 90 & 100 & \\
\hline
\end{tabular}

Tabel 8 menunjukkan bahwa antara pola makan kurang baik dengan kekambuhan gastritis memiliki hubungan yang signifikan.

Tabel 9. Hubungan tingkat stres dengan kekambuhan gastritis

\begin{tabular}{cccccccc}
\hline \multirow{2}{*}{$\begin{array}{c}\text { Tingkat } \\
\text { stres }\end{array}$} & \multicolumn{2}{c}{ Kekambuhan gastritis } \\
& \multicolumn{1}{c}{$\begin{array}{c}\text { Tidak } \\
\text { kambuh }\end{array}$} & Total & p \\
\cline { 2 - 6 } & $\mathbf{f}$ & $\%$ & $\mathbf{f}$ & $\%$ & $\mathbf{f}$ & $\%$ & \\
\hline Normal & 1 & 12,5 & 7 & 87,5 & 8 & 100 & \\
Ringan & 3 & 13,0 & 20 & 87,0 & 23 & 100 & \\
Sedang & 11 & 47,8 & 12 & 52,2 & 23 & 100 & 0,000 \\
Berat & 23 & 95,8 & 1 & 4,2 & 24 & 100 & \\
Cukup & 12 & 100 & 0 & 0 & 12 & 100 & \\
Berat & & & & & & & \\
Total & 50 & 55,6 & 40 & 44,4 & 90 & 100 &
\end{tabular}

Tabel 9 menunjukkan bahwa antara tingkat stres berat dan cukup berat dengan kekambuhan gastritis memiliki hubungan yang signifikan.

\section{PEMBAHASAN}

Berdasarkan Tabel 1. hasil pengolahan data yang dilakukan dalam penelitian menunjukkan bahwa mayoritas responden berumur antara 46-55 tahun 27,8 \%. Hal tersebut menunjukkan bahwa pada usia tersebut mungkin merupakan rentang usia produktif dan disertai dengan adanya kemunduran biologis terhadap fungsi organ tubuh. 
Tekanan dan tugas yang berlebihan pada usia produktif akan mempengaruhi pola makan yang kurang selektif dan juga mempengaruhi psikologis seseorang. Menurut Gustin (2011) menyatakan bahwa pada usia produktif sering berhadapan dengan tantangan dan apabila tidak dapat mengatasinya maka akan berpotensi menjadi sumber stres. Menurut Maulidiyah (2006) bahwa pertambahan usia pada usia produktif ini juga akan menimbulkan beberapa perubahan baik fisik maupun mental yang lebih lanjut, hal ini dapat mengakibatkan kemunduran biologis terhadap fungsi organ tubuh yang berperan dalam mempertahankan dan menciptakan kesehatan yang prima. Usia tua memiliki resiko yang lebih tinggi untuk menderita gastritis dibanding usia muda. Hal ini menunjukkan bahwa seiring dengan bertambahnya usia mukosa gaster cenderung menjadi tipis sehingga mudah terinfeksi Helicobacter pylori dan gangguan autoimun. $^{(4),(8)}$

Berdasarkan Tabel 2 hasil pengolahan data yang dilakukan dalam penelitian menunjukkan bahwa mayoritas responden berjenis kelamin perempuan $72,2 \%$. Pada usia dewasa terjadi perbedaan pola makan antara laki-laki dan perempuan ini disebabkan karena adanya perbedaan aktivitas dan komposisi tubuh. Dalam memilih makanan perempuan cenderung menghindari porsi yang banyak serta mengurangi frekuensi makan untuk menjaga penampilannya. Prevalensi gastritis pada perempuan lebih tinggi dibandingkan laki-laki, hal ini berkaitan dengan tingkat stres. Secara teori psikologis disebutkan bahwa perempuan lebih banyak menggunakan perasaan dan emosi sehingga rentan mengalami stres psikologis. ${ }^{(8),(10)}$

Hal ini tidak sesuai dengan Tarigan (2014) yang menyebutkan bahwa tukak gaster lebih sering terjadi pada laki-laki dibandingkan perempuan yaitu dengan perbandingan 3:2. Tetapi hal ini sesuai dengan teori Simadibrata dalam Maulidiyah (2006) yang mengatakan bahwa akhir-akhir ini kecenderungan insiden tukak gaster lebih sering pada perempuan dikarenakan perempuan lebih sering mengalami stres atau kecemasan dalam hidupnya. $^{(8),(20)}$
Berdasarkan Tabel 3 hasil pengolahan data yang dilakukan dalam penelitian menunjukkan bahwa mayoritas kejadian gastritis terjadi pada responden dengan pendidikan SD dan SMA 62,2\%. Tingkat pendidikan seseorang mempengaruhi daya tahan tubuhnya untuk mengahadapi stres, makin tinggi tingkat pendidikan seseorang main tinggi daya tahannya untuk melawan stres. Tingkat pendidikan juga berpengaruh terhadap pengetahuan seseorang mengenai kebiasaan makan yang baik. Menurut Soekirman (2000) Pemilihan bahan makanan dan pemenuhan kebutuhan gizi seseorang dapat dipengaruhi oleh latar belakang pendidikannya. Semakin tinggi tingkat pendidikan dan pengetahuan seseorang tidak akan mengurangi kejadian gastritis dan kekambuhan gastritis apabila individu tersebut tidak mengaplikasikan pengetahuannya. ${ }^{(21)}$

Berdasarkan Tabel 4 hasil pengolahan data yang dilakukan dalam penelitian menunjukkan bahwa mayoritas kejadian gastritis terjadi pada responden dengan pekerjaan sebagai ibu rumah tangga 34,4\%. Kejadian gastritis yang mayoritas terjadi pada ibu rumah tangga dapat disebabkan karena stres yang dialami. Banyaknya tuntutan pekerjaan dan tanggung jawab sebagai ibu rumah tangga dengan pekerjaan yang cenderung menoton dapat menimbulkan stres. Stres yang terjadi akan mempengaruhi perilaku ibu rumah tangga tersebut diantaranya kehilangan nafsu makan, perubahan pola tidur, penurunan produktifitas dan hal ini juga akan mempengaruhi kejiwaan berupa timbulnya kecemasan yang berlebihan, penurunan daya tahan tubuh dalam membuat keputusan. Apabila stres ini terjadi terus-menerus maka akan berdampak terhadap seseorang tersebut. ${ }^{(22)}$

Berdasarkan Tabel 8 hasil pengolahan data dengan uji Chi-square yang dilakukan dalam penelitian menunjukkan bahwa antara pola makan dengan kekambuhan gastritis memiliki hubungan yang signifikan. Sehingga hipotesis yang menyatakan "terdapat hubungan pola makan dengan kekambuhan gastritis" dapat diterima.

Penelitian yang dilakukan oleh Maulidiyah (2006) terhadap 90 responden yang menemukan hubungan signifikan antara pola makan dengan 
kekambuhan gastritis. Hasil ini didukung oleh penelitian yang dilakukan oleh Ariyana (2014) terhadap 88 responden yang menemukan hubungan signifikan antara pola makan dengan kekambuhan gastritis. ${ }^{(8),(23)}$

Secara alami lambung akan terus memproduksi asam lambung setiap waktu dalam jumlah yang kecil dengan volume $1500 \mathrm{ml} /$ hari. Pola makan yang kurang baik akan membuat lambung sulit untuk beradaptasi dalam pengeluaran sekresi asam lambung. Pola makan kurang baik merupakan salah satu penyebab meningkatnya produksi asam lambung dari segi faktor histaminergik dimana hal ini akan mempengaruhi kerja dari sel $G$ untuk produksi hormon gastrin dan juga terjadi defek barier mukosa dan difusi balik ion $\mathrm{H}^{+}$ yang akan merangsanh histamn untuk mempengaruhi kelenjer oksintik dalam produksi asam lambung. Jika hal ini berlangsung dalam waktu yang lama, produksi asam lambung akan meningkat secara berlebihan sehingga dapat mengiritasi dinding mukosa lambung menyebabkan gastritis. ${ }^{(20),(24)}$

Kekambuhan pada penderita gastritis salah satunya dapat dipengaruhi oleh pola makan yang kurang baik dimana akan terjadi peningkatan sekresi asam lambung yang dapat mengiritasi mukosa lambung kembali. Menurut Agus dalam Maulidiyah (2006) menyatakan bahwa salah satu penyebab munculnya kekambuhan gastritis karena ketidakmampuan lambung (indigesti), produksi asam lambung yang berlebihan akibat ketidakseimbangan faktor defensif dan faktor agresif yang menyebabkan produksi $\mathrm{HCl}$ dalam lambung meningkat dikarenakan pola makan yang kurang baik seperti cenderung konsumsi makanan pedas, konsumsi makanan atau minuman asam, waktu makan yang tidak teratur dan porsi makan yang berlebih. ${ }^{(8),(20)}$

Berdasarkan Tabel 9 hasil pengolahan data dengan uji Kruskall-wallis yang dilakukan dalam penelitian menunjukkan bahwa antara tingkat stres dengan kekambuhan gastritis memiliki hubungan yang signifikan. hipotesis "terdapat hubungan tingkat stres dengan kekambuhan gastritis" dapat diterima.
Menurut penelitian Gustin (2012) bahwa dari 30 responden yang mengalami gastritis didapatkan bahwa proporsi kejadian gastritis lebih tinggi pada responden yang mengalami stres dan hal ini juga dapat mempengaruhi terjadinya kekambuhan gastritis. Penelitian yang dilakukan oleh Maulidiyah (2006) terhadap 90 responden yang menemukan hubungan signifikan antara pola makan dengan kekambuhan gastritis. Menurut pendapat para ahli kedokteran menyatakan bahwa kenaikan asam lambung yang berlebihan dapat diakibatkan oleh stres atau ketegangan kejiwaan. ${ }^{(4),(8)}$

Secara alamiah pada periode interdigestif sekresi $\mathrm{HCl}$ terus berlangsung dalam kecepatan lambat 1-5 mEq/jam yang dikenal dengan BAO. Stres memiliki efek negatif melalui mekanisme neuroendokrin terhadap saluran pencernaan sehingga beresiko untuk mengalami gastritis. Rangsangan emosional kuat dapat meningkatkan BAO melalui saraf parasimpatis Nervus Vagus (NV). Rangsangan Nervus Vagus akan meningkatkan produksi $\mathrm{HCl}$ didalam lambung dengan cara mempengaruhi sel $G$ untuk mensekresi hormon gastrin yang berperan dalam sekresi asam lambung dan meningkatkan jumlah kelenjer oksintik untuk mensekresikan asam lambung secara berlebihan. Rangsangan emosional yang kuat dapat menyebabkan terjadinya peningkatan sekresi asam lambung $\geq 50 \mathrm{ml} / \mathrm{jam}$. Kadar $\mathrm{HCl}$ yang meningkat dapat mengiritasi mukosa lambung dan ini dapat menyebabkan terjadinya gastritis. Kekambuhan pada penderita gastritis salah satunya dapat dipengaruhi oleh stres psikologis dimana akan terjadi peningkatan sekresi asam lambung yang dapat mengiritasi mukosa lambung kembali. ${ }^{(16),(25)}$

\section{SIMPULAN}

Terdapat hubungan yang signifikan antara pola makan dengan kekambuhan gastritis.

Terdapat hubungan yang signifikan antara tingkat stres dengan kekambuhan gastritis. 


\section{DAFTAR PUSTAKA}

1. Kementerian Kesehatan RI. Pusat data dan informasi penyakit tidak menular. Jakarta: Kementerian Kesehatan RI; 2012.

2. Hirlan. Gastritis. Dalam: Setiati S, Idrus A, et al, editor (penyunting). IImu Penyakit Dalam. Jilid II Edisi ke-4. Jakarta: Balai Penerbit FKUI; 2014. hlm.1768-71.

3. WHO. Disease burden and mortality estimates. Global Health Observatory (GHO) data. 2013 (diunduh 5 November 2017). Tersedia dari: http://www.who.int/gho/ mortality burden disease/ en/index.html

4. Gustin RK. Faktor-faktor yang berhubungan dengan kejadian Kota Bukittinggi tahun 2011 (skripsi). Padang: Universitas Andalas. 2011;1-12.

5. Departemen Kesehatan RI (Depkes RI). Profil kesehatan Republik Indonesia. Jakarta; Depkes RI; 2012.

6. Dinas Kesehatan Provinsi Sumatera Barat. Profil Kesehatan Sumatera Barat 2014. Padang; Dinkes Sumbar; 2015.

7. National Institute of Diabetes and Digestive and Kidney Disease. Gastritis. 2014 (diunduh Nopember 2017). Tersedia dari: https://www.niddk.nih.gov/health-information/ digestive-disease/gastritis

8. Maulidiyah U. Hubungan antara stres dan kebiasaan makan dengan terjadinya kekambuhan gastritis (skripsi). Semarang: Universitas Airlangga. 2006.

9. Mansjoer A. Kapita selekta kedokteran. Edisi ke-3. Jakarta: Fakultas Kedokteran Universitas Indonesia; 2001.

10. Farida YB. Pengantar pangan dan gizi (artikel penelitian). Jakarta: Penerbit Swadaya; 2004.

11.Sulastri. Gambaran pola makan penderita gastritis di wilayah kerja Puskesmas Kampar Kiri Hulu Kecamatan Kampar Kiri Hulu Kabupaten Kampar Riau tahun 2012 (artikel penelitian). 2012 (diunduh Nopember 2017). Tersedia dari: https://jurnal.usu. ac.id/index.php/gkre/article/view/1051
12. Wahyu D. Pola makan sehari-hari penderita gastritis (artikel penelitian).Malang: Poltekkes Kemenkes. 2015.

13. Wendah $\mathrm{H}$. Hubungan pola makan dan stres dengan kejadian gastritis pada pasien yang berobat di Puskesmas Ramboken (buletin). Tomohon: Universitas Sariputra. 2016.

14. Noorhana SW. Faktor psikologik yang mempengaruhi kondisi medis. Jakarta: Badan Penerbit FKUI; 2010.

15. Pinel JPJ. Biopsikologi. Edisi ke-7. Yogyakarta: Pustaka Pelajar; 2009.hlm. 557-65.

16. Mayo Clinic. Stress symptomps: effect on your body, feelings and behavior. Mayo Found Med Educ Res 2017 (diunduh Nopember 2017). Tersedia dari: www.mayoclinic.org/healthylifestyle/stress-management/in-dept/stresssymptomps/

17. Handayani SD. Hubungan dukungan keluarga dengan kekambuhan pasien gastritis di Puskesmas Jatinangor (artikel penelitian). 2012 (diunduh Nopember 2017). Tersedia dari: http://jurnal.unpad.ac.id/ejournal/article/view/595

18. Dinas Kesehatan Kota Payakumbuh. Profil kesehatan Kota Payakumbuh. Payakumbuh: Dinkes Kota Payakmbuh; 2016.

19. Dahlan MS. Statistik untuk kedokteran dan kesehatan. Jakarta: Salemba Medika; 2012.

20. Tarigan P. Tukak gaster . Dalam: Setiati S, Idrus A, et al, editor (penyunting). IImu Penyakit Dalam. Jilid II Edisi ke-4. Jakarta: Balai Penerbit FKUI; 2014.

21. Soekirman. IImu gizi dan aplikasinya. Jakarta: Direktorat Jenderal Pendidikan Tinggi, Departemen Pendidikan Nasional; 2000.

22. Mumtahinnah N. Hubungan antara stres dengan agresi pada ibu rumah tangga yang tidak bekerja (artikel penelitian). Jakarta: Universitas Gunadarma. 2011.

23. Ariyana R. Hubungan pola makan dengan kekambuhan gastritis di poliklinik penyakit dalam 
rumah sakit umum daerah DR. Zainoel Abidin

Banda Aceh tahun 2014 (artikel penelitian). Aceh: Universitas Syiah Kuala. 2014.

24. Herman RB. Fisiologi pencernaan. Padang: Universitas Andalas; 2004.
25. Price SA, Lorraine MW. Konsep Klinis ProsesProses Penyakit. Dalam: Patofisiologi. Edisi ke-6. Terjemahan: Brahm U, Pendit, et al. Jakarta: EGC; 2005. 